\title{
Uncertainties in the relationship between high mean platelet volume and acute kidney injury after cardiac surgery
}

\author{
Cengiz Beyan, MD (D) Esin Beyan, MD
}

Received: 17 September 2020/ Accepted: 18 September 2020/Published online: 14 October 2020

(C) Canadian Anesthesiologists' Society 2020

\section{To the Editor,}

We carefully read the retrospective study of Ramakrishnan et al. suggesting that the high mean platelet volume (MPV) could be used to indicate acute kidney injury (AKI) associated with cardiac surgery. ${ }^{1} \mathrm{We}$ would like to express the presence of other factors that may have directly affected the MPV values of this study.

There is no standardized method to measure MPV, raising the question of whether MPV values should be used for purposes of making diagnoses or defining prognosis in patients with acquired diseases. ${ }^{2}$ After a blood sample is taken, the platelets that come into contact with the anticoagulant in the blood tube begin to swell and increase in diameter. This deviation changes the MPV values by $2-50 \%$, depending on the time from blood collection to measurement. ${ }^{3}$ Furthermore, the type of anticoagulant used in the complete blood count (ethylenediaminetetraacetic acid or citrate) can affect the optimal measurement time of MPV. ${ }^{3}$ The type of device used can also cause a variation of up to $40 \%$ in MPV measurements. ${ }^{3}$ These factors (time from blood collection, anticoagulant, device used) could all have adversely impacted the reliability of MPV data in the Ramakrishnan et al. study. Indeed, it is not possible to

This letter is accompanied by a reply. Please see Can J Anesth 2021; this issue.

\section{Beyan, MD $(\bowtie)$}

Faculty of Medicine, Ufuk University, Ankara, Turkey

e-mail: cengizbeyan@hotmail.com

E. Beyan, MD

Department of Internal Medicine, Kecioren Training and Research Hospital, University of Health Sciences, Ankara, Turkey exclude analysis errors in retrospective studies pertaining to MPV, as has been recently emphasized. ${ }^{4}$ Moreover, the Ramakrishnan et al. study also had statistically significant differences between patients with or without AKI in terms of age, sex, and race, all three of which have been reported to affect MPV values. ${ }^{2}$ An additional consideration is that the authors stated that the MPV increase indicates an increase in platelet aggregation. Studies using the gold standard light transmission platelet aggregation technique have not shown a correlation between platelet indices, including MPV, and platelet aggregation responses. ${ }^{5}$ In conclusion, there are many factors that make the association betweeen the change in MPV values and AKI after cardiac surgery uncertain.

Disclosures None.

Funding statement None.

Editorial responsibility This submission was handled by Dr. Hilary P. Grocott, Editor-in-Chief, Canadian Journal of Anesthesia.

\section{References}

1. Ramakrishnan A, Zheng C, Fontes $M L$, et al. Mean platelet volume and cardiac-surgery-associated acute kidney injury: a retrospective study. Can J Anesth 2020. https://doi.org/10.1007/s12630-02001811-4.

2. Noris $P$, Melazzini $F$, Balduini $C L$. New roles for mean platelet volume measurement in the clinical practice? Platelets 2016; 27: 607-12.

3. Beyan C, Beyan E. Were the measurements standardized sufficiently in published studies about mean platelet volume? Blood Coagul Fibrinolysis 2017; 28: 234-6.

4. Harrison P, Goodall AH. Studies on mean platelet volume (MPV) - new editorial policy. Platelets 2016; 27: 605-6. 
5. Beyan C, Kaptan K, Ifran A. Platelet count, mean platelet volume, platelet distribution width, and plateletcrit do not correlate with optical platelet aggregation responses in healthy volunteers. J Thromb Thrombolysis 2006; 22: 161-4.
Publisher's Note Springer Nature remains neutral with regard to jurisdictional claims in published maps and institutional affiliations. 